\title{
REDUÇÃO DO VOLUME DE UM RESÍDUO DE AZUL DE METILENO UTILIZANDO ENERGIA SOLAR
}

\author{
BARTMER, L. ${ }^{1}$; FURMAN, L. P. ${ }^{1}$; MEDEIROS, C. O. F. ${ }^{1}$; BUENO, K. L. ${ }^{1}$; SOUZA, T. R. ${ }^{1}$ \\ ${ }^{1}$ Universidade Federal do Pampa, Departamento de Engenharia Química, Campus Bagé \\ E-mail para contato: ligiabartmer@hotmail.com
}

\begin{abstract}
RESUMO - Órgãos de controle ambiental estabelecem padrões rigorosos para lançamento de efluentes líquidos ao meio ambiente, obrigando eficientes tecnologias de tratamento. Processos de pré-tratamentos, tem facilitado o tratamento final de efluentes líquidos, diminuindo o tempo de operação e custo total, como a evaporação, que consiste numa operação unitária que tem por finalidade concentrar soluções constituídas de solventes voláteis e solutos considerados não voláteis, pela evaporação parcial do solvente. O objetivo deste trabalho é utilizar um evaporador solar para realizar uma redução de volume, concentrando uma solução de azul de metileno, obtida como resíduo laboratorial. A inclinação do coletor solar é mantida em $20^{\circ}$ e a vazão de alimentação da solução em $0,0015 \mathrm{~kg} / \mathrm{s}$, valores esses determinados em experimentos anteriores. Os resultados obtidos mostram os valores das taxas de evaporação realizados a cada 30 minutos.
\end{abstract}

\section{INTRODUÇÃO}

Um dos assuntos mais discutidos na atualidade é a escassez e a falta de gerenciamento da água, que, segundo as previsões mais alarmantes, será motivo de grandes conflitos mundiais ainda neste século. Esses problemas se tornam mais ameaçadores quando se verifica o estado de degradação nas margens dos cursos d'água, devido principalmente a presença de atividades domésticas, agroindustriais e industriais. Essas atividades utilizam a água natural de forma indiscriminada e liberam seus efluentes de forma inadequada (Bahia, 2004).

Da mesma forma, a falta ou precariedade de saneamento básico, para grande parte da população do Brasil, implica no lançamento do lixo e dos efluentes domésticos em diversos cursos d'água. Os impactos decorrentes destes problemas têm se tornado crescente e coloca em risco a saúde da população que reside próximo a esses locais (Palz, 1981).

Os órgãos de controle ambiental têm estabelecido padrões cada vez mais rigorosos para o lançamento de efluentes líquidos ao meio ambiente, obrigando a implantação de eficientes tecnologias de tratamento. Os efluentes líquidos quando submetidos a um processo de prétratamento, tem facilitado o seu tratamento final, diminuindo o tempo de operação e custo total (Aldabó, 2002).

Um exemplo de pré-tratamento muito utilizado é a evaporação, que consiste numa operação unitária que tem por finalidade concentrar soluções constituídas de solventes voláteis e solutos considerados não voláteis, pela evaporação parcial do solvente. Como os 
solutos são considerados não voláteis, no equilíbrio a fase gasosa ou o evaporado só contém solvente, ou seja, a fração de solvente no evaporado é de $100 \%$. Na fase líquida, que é a solução a ser concentrada, há frações tanto de soluto quanto de solvente. Na evaporação, a energia é aplicada a um líquido a uma pressão constante, elevando a temperatura até o ponto de saturação, quando ele detém o máximo de energia possível sem entrar em ebulição. À medida que energia adicional é aplicada, a pressão de vapor do líquido atinge a pressão de vapor do ambiente adjacente e o líquido começa a vaporizar. O calor de vaporização é a quantidade de energia necessária para o líquido se transformar em vapor, sem mudança de temperatura. O vapor resultante se separa do líquido residual, aumentando a concentração da fração não volátil (Incropera e Witt, 1992).

O uso da evaporação solar para concentrar soluções diluídas (na maioria dos casos efluentes industriais) mostra-se eficaz com solutos prejudiciais à saúde ou ao meio ambiente, como o azul de metileno (Macedo, 1996).

A evaporação também pode ser usada na concentração de soluções visando apenas uma redução de volume, que segue para a destinação final ou descarte.

Alguns autores estudaram alternativas para a destinação final ou a utilização desta solução concentrada. Dentre esses autores destacam-se: Amorim et al. (2007), Soares et al. (2006) e Proença (2002).

Amorim et al. (2007), Soares et al. (2006) e Proença (2002) propõem a utilização da solução concentrada em piscinas especiais, visando à criação de certas espécies de peixes marinhos e de camarão, gerando uma renda extra para a família beneficiada com a dessalinização.

Uma das alternativas apresentada por Soares et al. (2006) e Proença (2002) foi uma redução do volume da solução pela evaporação solar, seguida de uma cristalização. Neste caso, o rejeito transforma-se em um produto sólido que poderá ser utilizado como complemento alimentar para animais (principalmente o gado).

Outra solução apontada por Amorim et al. (2007) e Soares et al. (2006), é a utilização da solução concentrada para irrigar plantas halófitas que apresentam alta tolerância aos sais e elevado poder nutritivo. Esse tipo de planta pode ser usado como alimento para a criação de animais, presentes na região.

A técnica de evaporação com aquecimento direto pode empregar a energia solar como combustível, pois consiste em fonte energética renovável e limpa, não emitindo poluente. Existem diferentes formas de utilizar a energia solar no aquecimento, concentração ou tratamento de águas. A principal delas é o aproveitamento da radiação solar como energia térmica em um evaporador solar. Souza et al. (2008) apresentaram a aplicação térmica da energia solar na concentração de soluções diluídas (efluentes industriais) como uma forma de uso de energia alternativa.

Observando essa tendência, o objetivo geral deste trabalho é utilizar um evaporador solar para concentrar uma solução de azul de metileno, reduzindo seu volume de forma 
ecologicamente correta. Esse fato é interessante, uma vez que os laboratórios da universidade pagam as empresas que realizam o tratamento de efluentes, por litro de solução enviada.

\section{METODOLOGIA}

A solução de azul de metileno foi escolhida por se tratar de um resíduo laboratorial, servindo de teste para redução de volume. Se a evaporação for eficiente para esse tipo de resíduo, será testada a evaporação solar de mais efluentes laboratoriais visando uma redução de custos com a destinação final de tais soluções, uma vez que os laboratórios da universidade pagam as empresas que realizam o tratamento de efluentes, por litro de solução enviada.

O esquema do evaporador solar utilizado no trabalho pode ser visualizado na Figura 1. Este equipamento encontra-se no laboratório de Fenômenos de Transporte da Universidade Federal do Pampa - UNIPAMPA, campus Bagé.

Figura 1 - Esquema do evaporador solar.

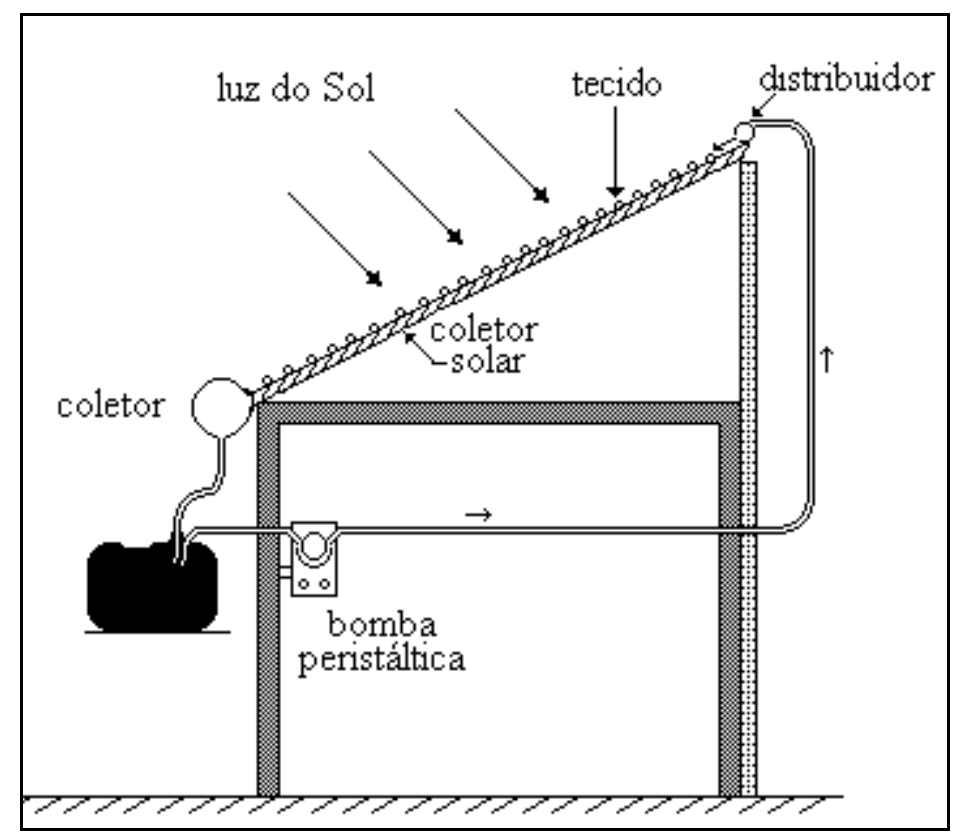

Os experimentos foram realizados mantendo a inclinação da placa fixa em $20^{\circ}$ e a vazão de alimentação em $2,5 \mathrm{Kg} / \mathrm{s}$. Esses valores foram determinados como o ponto onde se obteve maior taxa de evaporação em trabalhos anteriores, como: Souza et al. (2008) e Bartmer et al. (2015).

Todos os experimentos foram realizados de forma contínua das 9:00 as 16:30 horas, para verificar como o equipamento se comporta no decorrer de todo o dia. Vale a pena ressaltar que o fluído é alimentado na parte superior da placa, escoa sobre sua superfície, é coletado na parte inferior, sendo depositado em um recipiente negro, sendo novamente succionado por uma bomba até a parte superior da placa. O fluído se mantém em um ciclo fechado. 
A realização dos experimentos ocorreu em dias parecidos, em dias de sol pleno (sem nuvens), para manter a quantidade de radiação solar incidente o mais similar possível, em todos os dias que se realizaram os experimentos, atenuando os efeitos da diferença de incidência da radiação solar.

É necessário lembrar que as variáveis meteorológicas também interferem na taxa de evaporação, sendo constantemente monitoradas.

As medições dos dados experimentais, tais como: temperatura ambiente, umidade relativa, pressão atmosférica, temperatura do fluido (na entrada e na saída da placa) e vazão mássica do fluido (na entrada e na saída da placa) foram realizadas a cada 30 minutos.

\section{RESULTADOS} Tabela 1.

As medições dos dados ambientais a cada 30 minutos, podem ser visualizadas na

Tabela 1 - Valores das variáveis meteorológicas

\begin{tabular}{|c|c|c|c|c|c|c|}
\hline HORA & $\begin{array}{c}\text { Temperatura } \\
\text { Ambiente } \\
\left({ }^{\circ} \mathrm{C}\right)\end{array}$ & $\begin{array}{c}\text { Velocidade } \\
\text { do } \\
\text { Vento } \\
(\mathrm{Km} / \mathrm{h})\end{array}$ & $\begin{array}{c}\text { Umidade } \\
\text { Relativa } \\
(\%)\end{array}$ & $\begin{array}{c}\text { Irradiância } \\
\text { difusa } \\
\left(\mathrm{MJ} / \mathrm{m}^{2}\right)\end{array}$ & $\begin{array}{c}\text { Irradiância } \\
\text { direta } \\
\left(\mathrm{MJ} / \mathrm{m}^{2}\right)\end{array}$ & $\begin{array}{c}\text { Irradiância } \\
\text { global } \\
\left(\mathrm{MJ} / \mathrm{m}^{2}\right)\end{array}$ \\
\hline $09: 00$ & 21,4 & 0,04 & 58 & 0,360 & 0,504 & 0,864 \\
\hline $09: 30$ & 21,5 & 0 & 60 & 0,310 & 0,765 & 1,075 \\
\hline $10: 00$ & 21,6 & 0 & 62 & 0,220 & 1,001 & 1,221 \\
\hline $10: 30$ & 21,5 & 2 & 63 & 0,155 & 1,222 & 1,377 \\
\hline $11: 00$ & 22 & 6 & 61 & 0,109 & 1,466 & 1,575 \\
\hline $11: 30$ & 22,9 & 0 & 59 & 0,090 & 1,753 & 1,844 \\
\hline $12: 00$ & 23,8 & 0,01 & 58 & 0,103 & 1,914 & 2,017 \\
\hline $12: 30$ & 24,3 & 4 & 56 & 0,122 & 1,985 & 2,107 \\
\hline $13: 00$ & 24,3 & 3 & 54 & 0,130 & 2,025 & 2,155 \\
\hline $13: 30$ & 25,1 & 6 & 52 & 0,146 & 2,121 & 2,267 \\
\hline $14: 00$ & 26,2 & 5,9 & 49 & 0,132 & 2,171 & 2,303 \\
\hline $14: 30$ & 26,4 & 11,3 & 49 & 0,085 & 2,260 & 2,345 \\
\hline $15: 00$ & 27 & 7,3 & 46 & 0,113 & 2,185 & 2,298 \\
\hline $15: 30$ & 26,4 & 8,7 & 46 & 0,160 & 1,923 & 2,083 \\
\hline $16: 00$ & 26,8 & 6 & 45 & 0,220 & 1,312 & 1,532 \\
\hline $16: 30$ & 26,5 & 5,3 & 44 & 0,270 & 0,884 & 1,154 \\
\hline Média & $24,2 \pm 2,2$ & $4,1 \pm 3,5$ & $53,9 \pm 6,6$ & $0,17 \pm 0,08$ & $1,59 \pm 0,57$ & $1,76 \pm 0,5$ \\
\hline
\end{tabular}

$\mathrm{Na}$ Tabela 1 pode-se observar que os valores da temperatura ambiente aumentam gradativamente ao longo do dia, apresentando um pico de $26,8^{\circ} \mathrm{C}$ as $16: 00$ horas, enquanto os valores de umidade relativa diminuem. A velocidade do vento apresentou valores baixos ao longo de todo o dia. Os autores Furman et al. (2015) encontraram em experimento realizado na mesma estação do ano (primavera) e na mesma cidade os valores de temperatura ambiente de $21,5 \pm 2,3{ }^{0} \mathrm{C}$, velocidade do vento de $11,3 \pm 3,2 \mathrm{~km} / \mathrm{h}$ e umidade relativa de $62,8 \pm 6,8 \%$.

Os valores de radiação solar global e difusa, utilizados nesse trabalho, foram obtidos na Estação Meteorológica da Universidade de Santa Maria - RS, pois Bagé não dispõe desses dados. Mesmo com a distância de $250 \mathrm{~km}$ entre Bagé e Santa Maria, os valores de radiação podem ser utilizados com uma boa aproximação. 
Os valores de temperatura da solução dentro do reservatório, vazão de entrada e vazão de saída do fluído no equipamento, podem ser visualizadas na Tabela 2 a seguir, juntamente com os valores de porcentagem de evaporação.

Tabela 2 - Resultados da porcentagem de evaporação

\begin{tabular}{|c|c|c|c|c|}
\hline HORA & $\begin{array}{c}\text { Temperatura da } \\
\text { Solução } \\
\left({ }^{\circ} \mathrm{C}\right)\end{array}$ & $\begin{array}{c}\text { Vazão de } \\
\text { Entrada } \\
(\mathrm{Kg} / \mathrm{s})\end{array}$ & $\begin{array}{c}\text { Vazão } \\
\text { de } \\
\text { Saída } \\
(\mathrm{Kg} / \mathrm{s})\end{array}$ & $\begin{array}{c}\% \\
\text { Evaporação }\end{array}$ \\
\hline $09: 00$ & 19,6 & 0,0026 & 0,0023 & 9,37 \\
\hline $09: 30$ & 19,6 & 0,0025 & 0,0023 & 7,42 \\
\hline $10: 00$ & 19,8 & 0,0026 & 0,0023 & 13,87 \\
\hline $10: 30$ & 19,4 & 0,0026 & 0,0022 & 17,79 \\
\hline $11: 00$ & 20,5 & 0,0026 & 0,0022 & 15,78 \\
\hline $11: 30$ & 23,3 & 0,0026 & 0,0022 & 15,72 \\
\hline $12: 00$ & 24,4 & 0,0027 & 0,0023 & 14,31 \\
\hline $12: 30$ & 26,1 & 0,0026 & 0,0022 & 17,70 \\
\hline $13: 00$ & 26,3 & 0,0027 & 0,0022 & 18,49 \\
\hline $13: 30$ & 28,5 & 0,0026 & 0,0021 & 18,79 \\
\hline $14: 00$ & 25,2 & 0,0026 & 0,0024 & 8,87 \\
\hline $14: 30$ & 28,2 & 0,0026 & 0,0020 & 21,07 \\
\hline $15: 00$ & 34,1 & 0,0026 & 0,0023 & 11,40 \\
\hline $15: 30$ & 27,1 & 0,0026 & 0,0020 & 21,99 \\
\hline $16: 00$ & 27,6 & 0,0026 & 0,0020 & 23,40 \\
\hline $16: 30$ & 30,4 & 0,0026 & 0,0019 & 25,68 \\
\hline
\end{tabular}

$\mathrm{Na}$ Tabela 2, verifica-se que dentre todos os experimentos realizados, o que apresentou maiores valores de porcentagem de evaporação, ao longo de todo o dia foi o realizado as 16:30 horas. Este resultado seria esperado por análise física, uma vez que, nesse horário o ambiente apresentou maiores valores de temperatura ambiente e velocidade do vento e menores valores de umidade relativa. O fluído se mantém em um ciclo fechado e por isso a temperatura da solução vai aumentando ao longo do dia, favorecendo a evaporação. Esse favorecimento é verificado nos valores de taxa de evaporação, que se eleva durante todo o dia, mesmo o ambiente apresentando valores de radiação solar mais elevados por volta das 14:00 horas.

Vale a pena ressaltar que o volume inicial de solução era de 7 litros sendo reduzido para 0,2 litros.

\section{CONCLUSÃO}

O principal resultado foi à obtenção de taxas de evaporação consideráveis, o que nos leva a acreditar num futuro promissor para uso desse equipamento, não só nas cidades de teste como em todo o território nacional, uma vez que se trata de um equipamento barato, de fácil instalação e manutenção e ecologicamente correto para evaporar efluentes a partir da energia solar. 
Verificou-se uma redução de volume de 7 litros para 0,2 litros, ou seja, uma redução de $3500 \%$. Esses resultados comprovam a eficácia do uso de evaporador solar para reduzir o volume de efluentes.

Um fato interessante a ser destacado é que alguns autores não recomendam a instalação de equipamentos solares em cidades localizadas no sul do Brasil e esse trabalho mostra exatamente o contrário.

\section{REFERÊNCIAS}

ALDABÓ, R. (2002) Energia Solar. Artliber: São Paulo.

AMORIM, M. C. C.; PORTO, E. R.; SILVA JÚNIOR, L. G. A. (2007). Evaporação solar como alternativa de reuso dos efluentes da dessanilização por osmose inversa. Disponível em: <http://www.bvsde.paho.org/bvsaidis/aresidua/i-007.pdf>. Acesso em 17 jan. 2007.

BAHIA, G. Disponível em: <www.guilhermebahia.hpg.ig.com.br/pagina2.htm>. Acesso em: 09 jan.2004.

BARTMER, L. ; LAUERMANN， B. ; WOHLEMBERG， J. C. ; RODRIGUES， L. M. ; SOUZA, T. R. . Obtenção de Valores de Taxa de Evaporação em um Evaporador Solar. In: VII Simpósio de Energia e Meio Ambiente, 2015, Pelotas. Anais do VII Simpósio de Energia e Meio Ambiente, 2015.

FURMAN, L. P.; BARTMER, L.; LAUERMANN, B.; MESSA, A.; MELO, P. F. S.; RODRIGUES, L. M.; SOUZA, T. R. Otimização do funcionamento de um evaporador solar,. In: II Encontro de Ciências e Tecnológica do IF Sul Campus Bagé, 2015, Bagé. Anais do II Encontro de Ciências e Tecnológica do IF Sul Campus Bagé, 2015.

INCROPERA, F. P.; WITT, D. P. D. (1992) Fundamentos de transferência de calor e massa. Rio de Janeiro: Editora Guanabara Koogan S. A., 455.

MACEDO, H. (1996) Tratamento de águas com altas concentrações de cloretos. 1996. 79f. Dissertação (Mestrado em Engenharia Hidráulica e Sanitária) - Escola Politécnica, Universidade de São Paulo.

PALZ, W. Energia Solar e fontes alternativas. São Paulo: Hemus, 1980.

PROENÇA, C. N. O. (2002) Tecnologias limpas para preservação e conservação da qualidade dos recursos hídricos no semi-árido do estado da Bahia. 2002, 30f. Monografia - (Departamento de Hidráulica e Saneamento) - Escola Politécnica, Universidade Federal da Bahia.

SOARES, M. T.; SILVA, I. J. O. C.; DUARTE, S. N.; SILVA, E. F. F. (2006) Destinação de águas residuárias provenientes do processo de dessalinização por osmose reversa. Revista Brasileira de Engenharia Agrícola e Ambiental, v. 10, nº 3, p. $730-737$.

SOUZA, T. R. ; SALVAGNINI, W. M. ; CAMACHO, J. L. P. ; TAQUEDA, M. E. S. . Performance of a solar energy powered falling film evaporator with film promoter. Energy Conversion and Management, v. 49, p. 3550-3559, 2008. 